\title{
CRONOGRAMA DE MANTENIMIENTO DE UNIDADES TERMOELÉCTRICAS CONVENCIONALES EN UN MERCADO ELÉCTRICO COMPETITIVO
}

\section{Luis Salinas San Martin}

\section{RESUMEN}

La presente publicación propone un enfoque de planeamiento para elaborar un cronograma de mantenimiento óptimo de unidades termoeléctricas convencionales, en un mercado eléctrico competitivo, para satisfacer la demanda máxima de electricidad al costo mínimo en el largo plazo. Dicho enfoque se fundamenta en la aplicación, de manera iterativa, del Método de Descomposición de Bender en una red eléctrica en la que interactúan las Empresas de Generación Eléctrica (EGE) y el Operador Independiente del Sistema Eléctrico (OISE), con distintos objetivos en el mercado.

Palabras Clave: Cronograma de Mantenimiento, Unidades Generadoras, Mercado Eléctrico Competitivo, Despacho de Carga, Método de Descomposición de Bender.

DOI: $10.23881 /$ idupbo.018.1-11i 